\title{
Correction to: A challenging case of carbapenemase-producing Klebsiella pneumoniae septic thrombophlebitis and right mural endocarditis successfully treated with ceftazidime/avibactam
}

\begin{abstract}
Alessandra lacovelli ${ }^{1} \cdot$ Martina Spaziante $^{2} \cdot$ Samir Al Moghazi $^{1} \cdot$ Alessandra Giordano ${ }^{1}$. Giancarlo Ceccarelli ${ }^{1}$. Mario Venditti ${ }^{1}$
\end{abstract}

Published online: 10 July 2018

(c) Springer-Verlag GmbH Germany, part of Springer Nature 2018

\section{Correction to: Infection}

https://doi.org/10.1007/s15010-018-1166-9

The given names and family names of all authors were transposed in the original publication.

The original article has been corrected.

The original article can be found online at https://doi.org/10.1007/ s15010-018-1166-9.

Mario Venditti

mario.venditti@uniroma1.it

1 Department of Public Health and Infectious Diseases,

"Sapienza" University of Rome, Rome, Italy

2 Department of Clinical Medicine, "Sapienza” University of Rome, Rome, Italy 